\title{
Wunderlich's syndrome in a young man of testicular mixed germ cell tumor with choriocarcinoma syndrome
}

\author{
Yee-Huang Ku'; Huwi-Chun Chao ; Wen-Liang Yub ${ }^{3 *}$ \\ ${ }^{1}$ Division of Infectious Disease, Department of Internal Medicine, Chi Mei Medical Center-Liouying, Taiwan \\ ${ }^{2}$ Department of Intensive Care Medicine, Chi Mei Medical Center, Taiwan \\ ${ }^{3}$ Department of Medicine, Taipei Medical University, Taiwan
}

\author{
*Corresponding Author(s): Wen-Liang Yub \\ Associate professor, Department of Intensive Care \\ Medicine, Chi Mei Medical Center, 901 Chung Hwa Rd, \\ Tainan City, Taiwan
}

Tel: +886-6-2812811, Fax: +886-6-2833351

Email: Yuleon_md@yahoo.com.tw

Received: Nov 02, 2018

Accepted: Dec 20, 2018

Published Online: Dec 28, 2018

Journal: Journal of Case Reports and Medical Images

Publisher: MedDocs Publishers LLC

Online edition: http://meddocsonline.org/

Copyright: (C) Wen-Liang Y (2018). This Article is distributed under the terms of Creative Commons Attribution 4.0 International License

Keywords: Choriocarcinoma syndrome; Germ cell tumor; Wunderlich's syndrome

\section{Introduction}

Wunderlich's syndrome is a rare but potentially life-threatening entity of spontaneous renal hemorrhage into the formation of perirenal and/or sub capsular hematoma, mostly due to vasculitis and renal tumors, such as renal angiomyolipoma, which is a benign mesenchymal tumor and is the most frequent cause [1-4]. The greatest risks of angiomyolipoma for bleeding are tumor size and grade of the vascular component of the tumor, especially where a diameter more than $4 \mathrm{~cm}$ [5]. The patients of Wunderlich's syndrome could manifest with spontaneously non-traumatic renal rupture with characteristically unexpected large retroperitoneal hemorrhage. The classic presentation includes flank or abdominal pain, a palpable tender mass and

\begin{abstract}
Wunderlich's syndrome is a rare but potentially lifethreatening entity of spontaneous renal hemorrhage into the formation of perirenal and/or sub capsular hematoma, mostly due to vasculitis and renal tumors. We herein report a young man who was found to have Wunderlich's syndrome, which was associated with metastasis of testicular tumor. Wunderlich's syndrome was very rare to be associated with metastasis from testicular choriocarcinoma, together with metastatic brain germ cell tumor bleeding, characterizing components of choriocarcinoma syndrome in our case. This report draws attention of physicians to consider choriocarcinoma syndrome while dealing with life-threatening Wunderlich's syndrome.
\end{abstract}

gross hematuria. Other symptoms such as nausea, vomiting, fever, anaemia, acute renal failure and hypotension are observed less frequently [2].

\section{Case report}

We herein report a young man who was found to have Wunderlich's syndrome, which was associated with metastasis of testicular tumor. The 20-year-old man claimed no underlying disease. He suffered from nausea, headache, occasional fainting and severe pain over left flank area. The Computed Tomography (CT) of the abdomen revealed left perirenal hematoma (Figure 1A), which was compatible with Wunderlich's syndrome. Renal arteriography via right common femoral artery to study bilat-

Cite this article: Yee-Huang K, Huwi-Chun C, Wen-Liang Y. Wunderlich's syndrome in a young man of testicular mixed germ cell tumor with choriocarcinoma syndrome. J Case Rep Clin Images. 2018; 3: 1011. 
eral renal arteries revealed multiple tumor stains at left-sided kidney and almost loss of normal stain of left renal parenchyma (Figure 1B). The ongoing process of Wunderlich's syndrome involved bilateral kidneys 2 weeks later (Figure 1C).

Unsteady gait and drowsy consciousness were observed for the patient during hospital stay. The Magnetic Resonance Imaging (MRI) findings of the brain suspected metastasis in right frontal region (Figure 1D). The CT of the chest revealed multiple metastatic tumors (Figure 1E). He underwent emergent craniotomy to remove right frontal tumor. Then, an enlarging mass in the scrotum was found and pelvic CT showed a leftsided testicular tumor (Figure 1F). A very high level of $\beta$-human chorionic gonadotropin ( $\beta$-HCG) of greater than $225,000 \mathrm{IU} / \mathrm{mL}$ was detected, which was suspicious of choriocarcinoma. He underwent left-sided orchiectomy. The pathology of tissue biopsy from the right frontal tumor revealed malignant germ cell tumor of choriocarcinoma (Figure 1G), while the left testis biopsy disclosed mixed germ cell tumor, including choriocarcinoma, 70\%; yolk sac tumor, 20\% (Figure $1 \mathrm{H}$ ) and teratoma, 20\% (Figure 1I). Chemotherapy was given to treat germ cell tumor. However, he was found to lose consciousness with dilated pupils and died two weeks later.

\section{Discussion}

Testicular germ cell tumors are rare, accounting for only around $1-2 \%$ of all malignancies in males. Choriocarcinoma is most often seen as a component of mixed germ cell tumors in around $8-10 \%$ of cases. Choriocarcinomas most often metastasize early to other sites at the lung, liver and brain, and tend to hemorrhagic shock due to bleeding from metastatic sites of choriocarcinoma named choriocarcinoma syndrome [1-4]. A bleeding primary or metastatic choriocarcinoma of the kidney is rarely reported in the literature, which may present with fe- ver, gross hematuria and acute flank pain secondary to multiple micro aneurysms, hematoma and/or perinephric hemorrhage [6-9]. Wunderlich's syndrome was ever reported to be associated with choriocarcinoma in a young woman complicated with brain, mediastinum and abdomen metastases and retroperitoneal bleeding [10].

A genetic role, such as maspin-negative and mutant p53positive expression, is certain in the epidemiology of hydatid form mole, and complete moles appear to have the high risk of subsequent choriocarcinoma and metastasis [11]. In hydatid form mole, serum $\beta$-HCG is inversely correlated with maspin expression but is positively correlated with mutant $\mathrm{p} 53$ expression [12]. Trophoblast invasion is mediated through the major mediators of implantation, including the matrix metalloproteinase and epidermal growth factor, which transcription is mediated by positive p53 expression [13]. In addition, mdm-2 oncoprotein gene expression was detected significantly more frequently in testicular germ cell tumors from metastatic patients than in tumors from metastatic-free patients [14].

The management of Wunderlich's syndrome includes a conservative approach in the hemodynamically stable patients and active treatment in the unstable patients. Active treatment includes surgery or angioembolization. Massive hemorrhagic lesions can be managed with elective embolization and/or partial nephrectomy [5]. Our case presented with spontaneous renal bleeding with multiple intra-renal tumor stains. We believe that Wunderlich's syndrome of our patient might be associated with metastasis of testicular choriocarcinoma, together with metastatic brain germ cell tumor bleeding, characterizing components of choriocarcinoma syndrome.

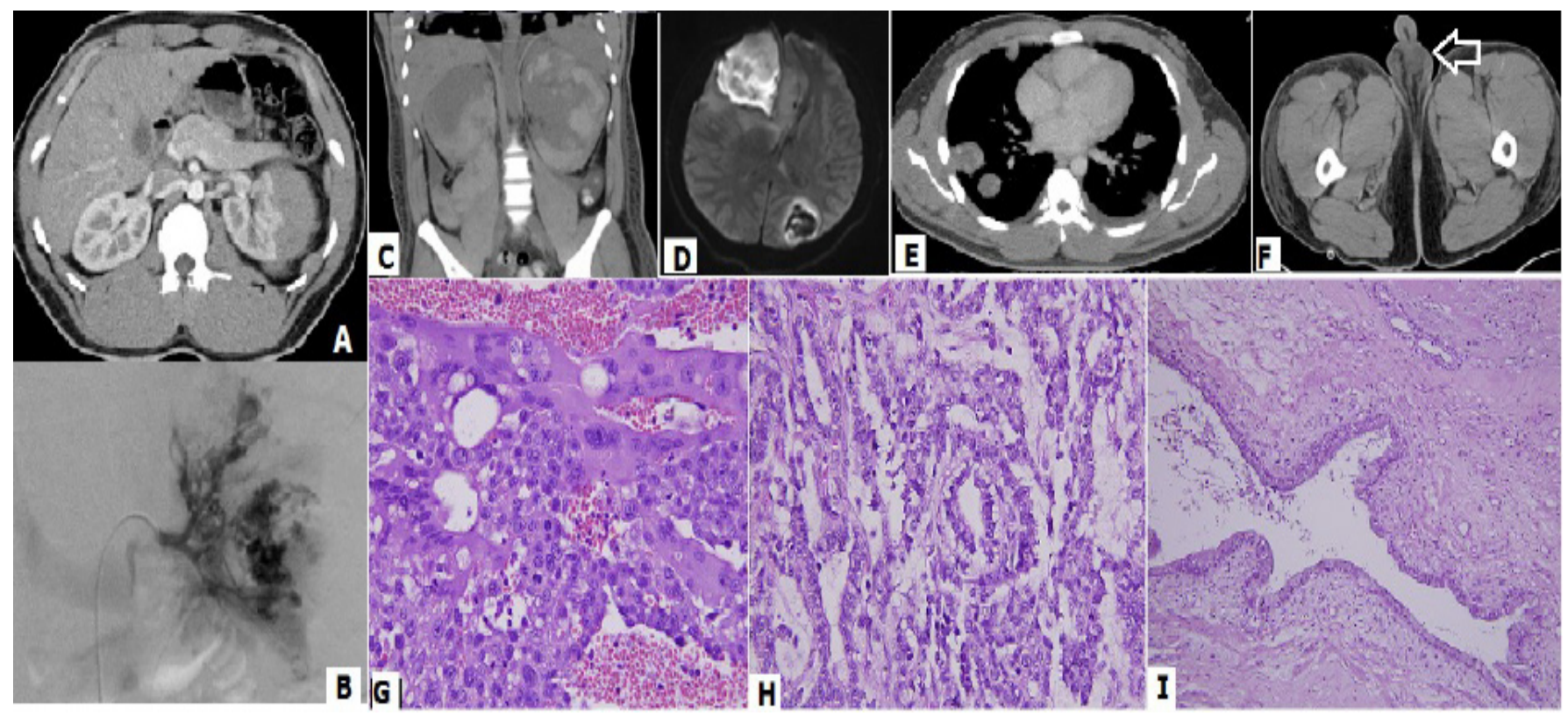

Figure 1: The Computed Tomography (CT) of the abdomen shows left perirenal hematoma (A). Renal arteriography reveals multiple tumor stains at left side kidney (B). The bleeding process shows ongoing involvement of bilateral kidneys 2 weeks later (C). The brain MRI shows right frontal base tumor with surrounding large hematoma and perifocal edema, causing mass effect, midline shifting and subfalcine herniation, as well as left high parietal hemorrhagic metastatic tumor (D). The CT scan of the chest is showing multiple metastatic tumors (E). The pelvic CT is showing left-sided testicular tumor (arrow) (F). The pathology of right frontal tumor tissue biopsy reveals choriocarcinoma (G). The left testis biopsy discloses mixed germ cell tumor, including choriocarcinoma, yolk sac tumor (H) and teratoma (I). 


\section{Conclusion}

Wunderlich's syndrome is one of the most feared complications of spontaneous non-traumatic renal hemorrhage. Our case draws attention of physicians to the importance of considering testicular choriocarcinoma syndrome while dealing with patients who manifests with Wunderlich's syndrome, as this syndrome is usually life-threatening.

\section{Ethics}

The above study has been granted exemption from review by the Institutional Review Board of Chi-Mei Medical Center (application no. 10606-E05).

\section{References}

1. Yeh $\mathrm{CY}$, Yang $\mathrm{HH}, \mathrm{Yu}$ WL. First report of immunogenic vasculitis with Wunderlich's syndrome following influenza B infection in a previously immunocompetent woman. J Formos Med Assoc. 2018; 117: 164-165.

2. Medda M, Picozzi SC, Bozzini GL. Wunderlich's syndrome and hemorrhagic shock. J Emerg Trauma Shock. 2009; 2: 203-205.

3. Oesterling JE, Fishman EK, Goldman SM, Marshall FF. The management of renal angiomyolipoma. J Urol. 1986; 135: 11211124.

4. Baagar K, Khan FY, Alkuwari E. Choriocarcinoma syndrome: a case report and a literature review. Case Rep Oncol Med. 2013; 2013: 697251.

5. Chiancone F, Mirone V, Imbimbo C, Pucci L, Meccariello C, et al. Emergency embolization of actively bleeding small renal angiomyolipoma with a fast growth in four months. Urologia. 2015; 82: 106-108.

6. Huang $\mathrm{CH}, \mathrm{Chen} \mathrm{L}, \mathrm{Hsieh} \mathrm{HH}$. Choriocarcinoma presenting as a unilateral renal mass and gross hematuria in a male: report of a case. J Formos Med Assoc. 1992; 91: 922-925.
7. Vijay RK, Kaduthodil MJ, Bottomley JR, Abdi S. Metastatic gestational trophoblastic tumour presenting as spontaneous subcapsular renal haematoma. Br J Radiol. 2008; 81: e234-e237.

8. Chang IB, Cho BM, Park SH, Yoon DY, Oh SM. Metastatic choriocarcinoma with multiple neoplastic intracranial microaneurysms: case report. J Neurosurg. 2008; 108: 1014-1017.

9. Mastrodomenico L, Korobkin M, Silverman PM, Dunnick NR. Perinephric hemorrhage from metastatic carcinoma to the kidney. J Comput Assist Tomogr. 1983; 7: 727-729.

10. Ojendiz-Nava RC, Niebla-Cárdenas D, Hernández-Flores SE, Audifred-Salomón JR, Morales-Leyte AL. Metastatic choriocarcinoma associated with Wunderlich syndrome: case report and literature review. Ginecol Obstet Mex. 2015; 83: 189-194.

11. Bracken MB, Brinton LA, Hayashi K. Epidemiology of hydatid form mole and choriocarcinoma. Epidemiol Rev. 1984; 6: 52-75.

12. Sun $\mathrm{P}, \mathrm{Wu} \mathrm{Q}$, Ruan $\mathrm{G}$, Zheng $\mathrm{X}$, Song $\mathrm{Y}$, et al. Expression patterns of maspin and mutant p53 are associated with the development of gestational trophoblastic neoplasia. Oncol Lett. 2016; 12: 3135-3142.

13. Staun-Ram E, Goldman S, Shalev E. p53 Mediates Epidermal Growth Factor (EGF) induction of MMP-2 transcription and trophoblast invasion. Placenta. 2009; 30: 1029-1036.

14. Eid H, Institoris E, Géczi L, Bodrogi I, Bak M. mdm-2 expression in human testicular germ-cell tumors and its clinical value. Anticancer Res. 1999; 19: 3485-3490. 